\title{
Endoscopic Endonasal Approaches to Craniovertebral Junction Pathologies: A Single-Center Experience
}

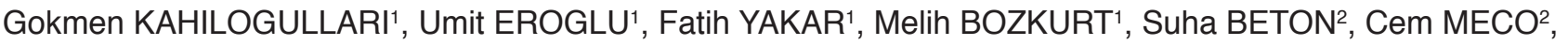 \\ Yusuf Sukru CAGLAR ${ }^{1}$
}

\begin{abstract}
${ }^{1}$ Ankara University School of Medicine, Ibni Sina Hospital, Department of Neurosurgery, Ankara, Turkey
${ }^{2}$ Ankara University School of Medicine, Ibni Sina Hospital, Department of Otolaryngology-Head and Neck Surgery, Ankara, Turkey
\end{abstract}

Corresponding author: Gokmen KAHILOGULLARI gokmenkahil@hotmail.com

\section{ABSTRACT}

AIM: To review our experience of using the endoscopic endonasal approach for clivus and odontoid pathologies as well as craniovertebral junction anomalies at our institution.

MATERIAL and METHODS: We retrospectively evaluated 41 patients (21 male, 20 female; age range, 2-65 years) who underwent endoscopic endonasal procedures for craniovertebral junction pathologies between 2008 and 2017.

RESULTS: Of the 41 patients, 27 had clivus lesions, 7 had odontoid lesions, 6 had basilar invagination, and 1 had rhinorrhea repair. Six patients underwent an additional posterior decompression/fusion either before or after the endonasal procedure. None of the patients required tracheostomy, and cerebrospinal fluid leakage was postoperatively detected in one patient. The patients' mean modified Rankin scale and visual analog scale scores were 3 and 4, respectively. The follow-up period ranged from 12 to 50 months.

CONCLUSION: Although the microscopic transoral approach has been considered the gold standard for craniovertebral junction surgical management, endoscopic approaches are feasible, safe, and effective for addressing pathologies in this region, with developing technique and surgical experience.

KEYWORDS: Endoscopy, Craniocervical junction, Clivus, Odontoid

\section{INTRODUCTION}

$\mathrm{T}$ The craniovertebral junction (CVJ) forms a transition between the brain and cervical spine and comprises the foramen magnum, atlas (C1), axis (C2), and ligaments and musculature associated with the $\mathrm{C} 1-\mathrm{C} 2$ vertebrae. Various congenital, developmental, and acquired pathologies can result in the compression of the bulbomedullary junction. However, the surgical management of CVJ pathologies remains a challenge because of the unique anatomical and biomechanical features of this region (36).

The traditional procedure for decompression of the ventral brainstem related to CVJ pathologies is the microsurgical transoral approach (TOA) with posterior fixation (11). Although CVJ is easily accessible with TOA, this approach has some disadvantages, including increased risks of contamination from oral flora and oral cavity/oropharynx injury, prolonged intubation, and enteral nutrition requirement $(47,61)$. TOA can therefore be associated with remarkable morbidity (35), and safer ways to access CVJ are being sought (3).

Improvements in endoscopic technology have provided safe and effective alternatives for accessing CVJ, enabling a wide exploration for surgeons and rendering TOA unnecessary (22). Many anatomical studies have demonstrated the feasibility of reaching this area via an endoscopic endonasal approach
Gokmen KAHILOGULLARI (D) : 0000-0001-8137-0510 Umit EROGLU

Fatih YAKAR
(D) : $0000-0001-8623-071 \mathrm{X}$
(D) : $0000-0001-7414-3766$
Melih BOZKURT (D) : 0000-0001-7433-081X

Suha BETON

Cem MECO

: 0000-0001-8195-4380

(D) : 0000-0001-8372-8045
Yusuf Sukru CAGLAR

0000-0003-4989-3965 
(EEA) $(3,27,31,59)$. In 2005, Kassam et al. (28) described an expanded EEA that has been performed world wide and modified it $(1,2,21,33,60,63)$. In the present study, we present our experience of using EEA for CVJ pathologies at our institute, with a review of the associated literature.

\section{MATERIAL and METHODS}

\section{Patients}

In this retrospective study, we evaluated 41 patients who underwent EEA procedures for basilar invagination, clivus, and odontoid pathologies at our institute between 2008 and 2017. All the patients provided written informed consent. All data about the patients were obtained by file scanning, telephone calls with patients, and face-to-face interviews. In the preoperative period, all patients underwent computed tomography (CT) scans, magnetic resonance imaging (MRI), and dynamic cervical radiograph studies to assist with navigation during the procedure. Medications for rheumatoid arthritis were discontinued for 15 days before and after surgery.

\section{Surgical Procedure}

Ear-Nose-Throat (ENT) surgeons accompanied our team during all endoscopic procedures, using a two-surgeon, four-handed technique. All the procedures were performed under general anesthesia with orotracheal intubation. The patients were positioned supine on a radiolucent operating table with the head in slight flexion, tilted slightly toward the surgeon, without using a fixation system. An antibiotic infusion was performed for infection prophylaxis, and the nasal mucosa was infiltrated with lidocaine and epinephrine. For all procedures, $0^{\circ}$ and $30^{\circ}$ wide-angle endoscopes were used with a neuronavigation system (Karl Storz, Tuttlingen, Germany) for confirming anatomical areas during all stages of the procedure and neurophysiological monitoring of motor and somatosensory evoked potentials. A portion of the upper leg was prepared for possible fat or fascia lata graft.

The nasoseptal flap was elevated, and following the bilateral out fracture of the inferior turbinates, endonasal access to the nasopharynx was ensured via both nares. The inferior nasal meatus was used as a guide to directly access the nasopharynx overlying CVJ. The eustachian tubes lie approximately at the level of the occiput-C1 junction, acting as an important landmark for the lateral limit of exposure. We palpated the anterior tubercle of $\mathrm{C} 1$ and confirmed this with neuronavigation. A midline vertical linear incision was made using monopolar cautery. We dissected myomucosal layer subperiosteally and exposed the $\mathrm{C} 1$ anterior arch, dens, and lower clivus. A high-speed drill was used to remove $\mathrm{C} 1$ and odontoid, leaving the posterior cortical shell and ligamentous attachments in place. A Kerrison rongeur or micro dissector was then used to remove the cortical shell and ligaments. The dura was visualized to confirm sufficient decompression. Intraoperative CT was used for all odontoidectomy and posterior fusion procedures. In addition, intraoperative X-ray was used for all posterior fusion procedures. In case of a cerebrospinal fluid (CSF) leak, the protocol was to repair the dural injury with the placement of a fat or fascia lata graft and fibrin glue or a Foley balloon and lumbar drain.

\section{Postoperative Care}

Following the procedure, all patients were extubated in the operating room. No imaging study was performed if the patient was neurologically intact. Prophylactic antibiotics were routinely used for 5 days, but if a CSF leak occurred, this was extended to 7 days and the drainage was retained for 7 days; patients who had a Foley balloon placed were provided close respiratory follow-up. After an evaluation of swallowing, a liquid diet was started. Nasal merocel packs were usually removed on postoperative day 5 , but they were removed on day 7 in case of a CSF leak. After discharge, the operation field was controlled endoscopically on postoperative day 15. Modified Rankin scale was used to measure the degree of disability or dependence in the daily activities with 0-6 points (decreasing disability), wherein zero point indicated no symptom and 6 points indicated death. Visual analog scale (VAS) was used to measure the pain intensity: the scale was anchored by no pain (score $=0$ ) and worst imaginable pain $($ score $=10)$.

\section{RESULTS}

This case series review included 21 male patients $(51 \%)$ and 20 female patients (49\%), with ages ranging from 2 to 65 years (mean, $38 \pm 12$ years). Table I presents the common symptoms in patients. The mean duration of symptoms was $20 \pm 13$ months. The most common medical condition was rheumatoid arthritis (five patients, 12\%); the mean age of patients with rheumatoid arthritis was $44 \pm 12$ years. The indications for surgery are presented in Table II.

The most common causes of CVJ compression were clivus chordoma $[n=17(41 \%)$, Figure $1 A, B]$, basilar invagination $[\mathrm{n}=6,(14.5 \%)]$, and rheumatoid arthritis $[\mathrm{n}=5,(12 \%)]$. Odontoidectomy (Figure 2A, B) was the second common procedure and was performed in 13 patients (31\%). Only one patient $(2.5 \%)$ needed further surgery after clivus chordoma resection because of rhinorrhea. Pneumocephalus without CSF leakage occurred in one pediatric patient after endoscopic odontoidectomy; this disappeared in a week with follow-up, and we published this complication as a lesson learned (26). The second rhinorrhoea case was of a patient who suffered from trauma and had clivus fracture. Rhinorrhoea repair and lumbar drainage were performed, and the patient's condition improved postoperatively.

Six patients (14.6\%) underwent additional posterior fusion involving the occiput and/or cervical spine (Figure 2C). All

Table I: Presenting Symptoms of the Patients

\begin{tabular}{lc}
\hline Symptom & $\begin{array}{c}\text { Number of } \\
\text { Patients (\%) }\end{array}$ \\
\hline Myelopathy & $25(60)$ \\
\hline Dysphagia & $12(29)$ \\
\hline Neck stiffness & $6(14)$ \\
\hline
\end{tabular}


Table II: Pathologies of the Patients

\begin{tabular}{lc} 
Pathology & $\begin{array}{c}\text { Number of Patients } \\
\text { (n=41) }\end{array}$ \\
\hline Clivus lesions & $\mathbf{n}(\%)$ \\
Chordoma & $17(41)$ \\
Cholesterol granuloma & $2(5)$ \\
Chondrosarcoma & $1(2.5)$ \\
Chondroblastoma & $1(2.5)$ \\
Squamous cell carcinoma metastasis & $1(2.5)$ \\
Undifferentiated round cell and spindle & $1(2.5)$ \\
cell sarcoma & \\
Meningioma & $1(2.5)$ \\
Plasmacytoma & $1(2.5)$ \\
Fibrous dysplasia & $1(2.5)$ \\
Angiomyoma & $1(2.5)$ \\
Rhinorrhea repair (Clivus fracture) & $1(2.5)$ \\
\hline Odontoid lesions & $\mathbf{n}(\%)$ \\
Rheumatoid arthritis pannus & $5(12)$ \\
Hydatid cyst (6) & $1(2.5)$ \\
Enchondroma & $1(2.5)$ \\
Basilar invagination (Occipitocervical & $6(14.5)$ \\
malformation with anterior & \\
compression) & \\
\hline &
\end{tabular}

posterior approaches were performed in the same session. The remaining 36 patients $(85.4 \%)$ did not require additional posterior decompression or fusion.

None of the patients required tracheostomy, but one patient (2.5\%) needed reintubation for a day following surgery. No oral nutrition was given during the first 5 postoperative days; after oral nutrition was initiated in three patients $(7 \%)$ who postoperatively required nasogastric tube feeding for a duration of 5-10 days. No patient required enteral nutrition support. No patient experienced velopharyngeal insufficiency. No CSF leakage was detected intraoperatively, but CSF leakage was detected in one patient postoperatively $(2.5 \%)$; lumbar drainage was performed, but the patient required reoperation for repair. None of the patients died.

The patients' mean modified Rankin scale and VAS scores were 3 and 4, respectively. The mean follow-up time was $40 \pm$ 10 months (range, 12-50 months). Neurological improvement was observed in 36 patients $(85.4 \%)$; the other six patients (14.6\%) were neurologically stable.

\section{DISCUSSION}

The physiological criteria and guidelines for the management of CVJ pathologies were well defined by Menezes et al. in the
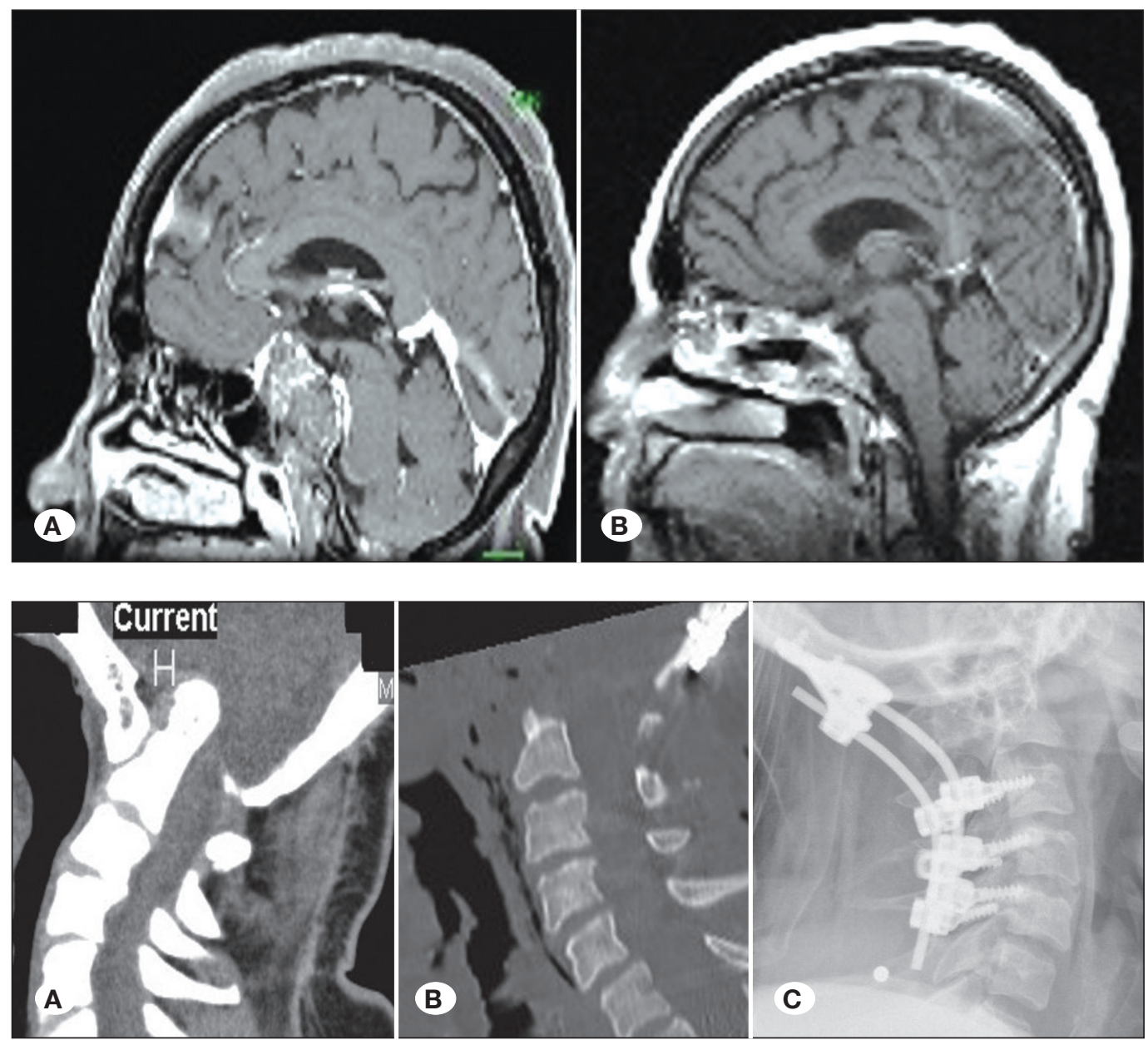

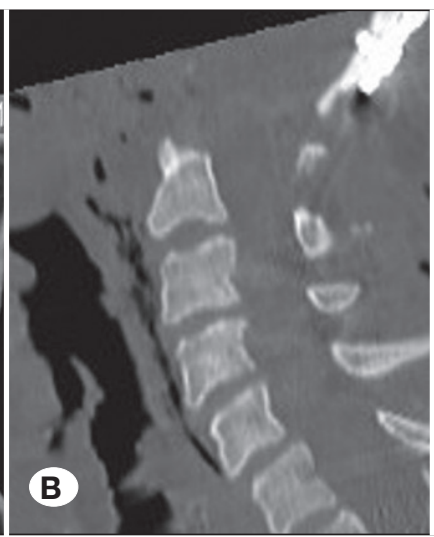

C
Figure 1: (A) A 57-yearold woman diagnosed with clivus chordoma on sagittal T1-weighted contrast-enhanced magnetic resonance imaging (MRI). (B) After performing the procedure via an endoscopic endonasal approach, postoperative MRI demonstrated that the lesion had been totally resected.

Figure 2: A 32-year-old man with dysphagia. (A) Computed tomography of the craniocervical junction showed basilar invagination. (B) The patient underwent endoscopic odontoidectomy and the compressive bone segment was totally resected. (C) Posterior fusion was performed during the same session. 
1980s $(40,41,51)$; this resulted in TOA gaining popularity. TOA alone or with extended modification by addition of mandibulotomy, mandibuloglossotomy, palatotomy, or transmaxillary approaches (62), has traditionally been considered the gold standard for ventral CVJ pathologies $(12,13,23,34,39)$, because it provides the most direct access (32).

The standard TOA is optimal for midline extradural lesions that are located behind the inferior clivus down to the $\mathrm{C} 2$ vertebral body. For lesions that involve the sphenoid sinus and upper/ middle clivus, the recommended approaches are transpalatal, transmaxillary (Le Fort I maxillotomy), or transmaxillary with a midpalatal split (extended "open-door" maxillotomy) $(4,25,50)$. A median labiomandibular glossotomy or a mandibular swing-transcervical approach may be required for lesions that extend more inferiorly from C2 to C4 $(15,43)$. Palatal division carries the risk of phonation dysfunction and velopharyngeal insufficiency.

Deconstruction of the facial skeleton (transmaxillary/transmandibular) can result in cosmetic deformity. Tracheostomy can be required following TOA if there is prolonged intubation or tongue swelling, or gastrostomy if the patient has difficulty swallowing (60). There is also a risk of oral flora contamination owing to the pharyngeal incision. With EEA, the incision along the posterior wall of the nasopharynx is smaller. However, with TOA, the transoral dissection is located more caudally, so the risk of oral flora contamination is greater $(9,12,24,47,60)$.

The aperture of the mouth and the presence of micrognathia and/or macroglossia can be restrictive factors during TOA $(33,37,38)$. Choi and Crockard reviewed 500 operations that were performed using TOA/extended approaches and reported the following complication rates: CSF leakage, $1.2 \%$ (6/500); respiratory problems (detailed information not given), 3\% (15/500); velopharyngeal incompetency, $6.6 \%$ (33/500); and death, $6.4 \%$ (32/500) (8). In a review of transoral odontoidectomies, Komotar et al. reported that 14 of 351 cases $(4.0 \%)$ resulted in velopharyngeal incompetency (29). The complication rates in both studies were considerably higher than those found in a literature review of the endonasal approach.

In recent years, EEA to the craniovertebral junction has been proposed as an alternative procedure to the standard TOAs $(2,3,5,17,19,20,22,24,28,33,37,38,42,44-47,49,55,56)$. The applicability of endoscopic endonasal odontoidectomy was first described in 2002 by Alfieri et al. in cadaveric studies (3). Following anatomical studies, Kassam et al. (28) reported the first successful EEA to CVJ.

An advantage of the endonasal route is the anatomical corridor that allows a deep located area to be reached with a wide and panoramic view $(1,47,64,65)$. However, the EEA procedure has some limitations. The operation field is really narrow, limited to the area from the lower clivus to the atlas rim in a rostral-caudal direction, approximately $1 \mathrm{~cm}$ from the midline mediolaterally. El Sayed et al. and de Almeida et al. have identified anatomical landmarks for EEA $(14,18)$. The back of the hard palate limits the rostral exposure to the CVJ lesion and ventral brainstem or upper cervical spinal cord (14).
Odontoidectomy is possible via this surgical corridor, but it is insufficient for a total C2 corpectomy. EEA cannot be fully successful for lesions that extend laterally to the lower cranial nerves (30). In addition, EEA limits the feasibility of dural repair (61). The vertebral artery is at risk during EEA procedures for CVJ pathologies; to minimize this risk, Yen et al. suggested that deviation from the midline should be avoided and neuromonitoring should be performed (61).

The technological evolution of EEA provides neuronavigation, neurophysiological monitoring, and intraoperative imaging to neurosurgeons. The standard approach in our institution is to use neuronavigation and monitoring during EEA. In addition, intraoperative CT is standard for odontoidectomy and posterior fusion. Choudhri et al. reported that the use of navigation and imaging is useful in understanding skull base anatomy as well as limiting the morbidity (10).

Fuji et al. prepared a systematic review and reported the most common pathology as basilar invagination (60.6\%); however, the most common pathology in our study was clivus chordoma (41\%) (20). Posterior fusion rate was $81 \%$ in the review (20) but only $14.6 \%$ in our study. Tracheostomy requirement and reintubation rates were $8.8 \%$ and $3.5 \%$, respectively, in the review (20), whereas these rates were $0 \%$ and $2.5 \%$, respectively, in our study. The nasogastric feeding rate was reported to be the same $(7 \%)$ in the systematic review and our study (20). The review (20) reported the rate of intraoperative CSF leak as $11.3 \%$, whereas we reported only one case of intraoperative leak (2.5\%).

Yen et al. performed 13 odontoidectomy, and the frequency of pathologies was as follows: rheumatoid arthritis (38.5\%), trauma (31\%), os odontoideum (15.3\%), ankylosing spondylitis (7.6\%), and postinfectious deformity (7.6\%) (61). Occipitocervical malformation with anterior compression $(5 / 12$ cases, $41.6 \%)$ was reported as the most common cause for odontoidectomy by Zenga et al. (64). In our study, the most common cause of odontoidectomy was occipitocervical malformation with anterior compression (6/13 cases, $46 \%)$ followed by rheumatoid arthritis pannus (5/13 cases, $38.5 \%$ ). Thus, the results in the literature are incompatible with each other because of the presentations of odontoidectmies are usually case series with a small number of patients.

Several authors have compared TOA and EEA $(2,47,54,57,64)$. In a study of head cadavers, Baird et al. reported that the distance to CVJ was shorter than that to EEA (5). Seker et al. reported that EEA offers the shorter route to CVJ, although TOA provided a wider opening (52). Shidoh et al. reported that EEA was a less invasive and more useful surgical procedure for clival chordomas; however, if the tumor was situated around CVJ, EEA was of limited use and thus TOA should be considered (53). Ponce-Gómez et al. have suggested EEA for odontoidectomy because of its effectiveness, feasibility, and the reduction in complication rates (47). Deopujari et al. used combined nasal and oral endoscopic approaches, reporting low rates of postoperative complications following endoscopic procedures (16). Visocchi et al. declared that EEA alone is superior if a CVJ lesion reaches the upper limit of the inferior third of the clivus (58). Shriver et al. reported that there was no significant difference in complication rates 
without postoperative tracheostomy requirement (54). The requirement for tracheostomy was statistically higher in the transoral group (54). In addition, an endoscopic TOA has been described for decompression of CVJ lesions $(7,18,46,48)$.

\section{CONCLUSION}

The surgical management of CVJ pathologies remains a challenge for surgeons. Although TOA has been considered the gold standard in CVJ surgery, anatomical and clinical studies over the last decade have shown EEA methods to be superior.

\section{ACKNOWLEDGEMENTS}

Preparation for publication of this article is partly supported by Turkish Neurosurgical Society.

\section{- REFERENCES}

1. Abuzayed B, Tanriover N, Gazioglu N, Akar Z: Extended endoscopic endonasal approach to the clival region. J Craniofac Surg 21: 245-251, 2010

2. Abuzayed B, Tanriover N, Gazioglu N, Ozlen F, Eraslan BS, Akar Z: Extended endoscopic endonasal approach to the anterior cranio-vertebral junction: Anatomic study. Turk Neurosurg 19: 249-255, 2009

3. Alfieri A, Jho HD, Tschabitscher M: Endoscopic endonasal approach to the ventral cranio-cervical junction: Anatomical study. Acta Neurochir (Wien) 144: 219-225, 2002

4. Ammirati M, Bernardo A: Analytical evaluation of complex anterior approaches to the cranial base: An anatomic study. Neurosurgery 43: 1398-1407, 1998

5. Baird CJ, Conway JE, Sciubba DM, Prevedello DM, QuinonesHinojosa A, Kassam AB: Radiographic and anatomic basis of endoscopic anterior craniocervical decompression: A comparison of endonasal, transoral and transcervical approaches. Neurosurgery 65 Suppl 6:158-164, 2009

6. Caglar S, Bozkurt M, Kahilogullari G, Ozdemir M: Management of a rare and dangerous infectious lesion: Hydatid cyst disease of the odontoid process. WScJ 3: 29-32, 2012

7. Chan AK, Benet A, Ohya J, Zhang X, Vogel TD, Flis DW, El-Sayed IH, Mummaneni PV: The endoscopic transoral approach to the craniovertebral junction: An anatomical study with a clinical example. Neurosurg Focus 40: E11, 2016

8. Choi D, Crockard HA: Evolution of transoral surgery: Three decades of change in patients, pathologies, and indications. Neurosurgery 73: 296-303, 2013

9. Choi $D$, Gleeson M: Surgery for chordomas of the craniocervical junction: Lessons learned. Skull Base 20:41-45, 2010

10. Choudhri O, Mindea SA, Feroze A, Soudry E, Chang SD, Nayak JV: Experience with intraoperative navigation and imaging during endoscopic transnasal spinal approaches to the foramen magnum and odontoid. Neurosurg Focus 36: E4, 2014

11. Crockard HA: The transoral approach to the base of the brain and upper cervical cord. Ann R Coll Surg Engl 67:321-325, 1985
12. Crockard HA: Transoral surgery: Some lessons learned. $\mathrm{Br} \mathrm{J}$ Neurosurg 9: 283-293, 1995

13. Crockard HA, Pozo JL, Ransford AO, Stevens JM, Kendall BE, Essigman WK: Transoral decompression and posterior fusion for rheumatoid atlanto-axial subluxation. J Bone Joint Surg Br 68: 350-356, 1986

14. de Almeida JR, Zanation AM, Snyderman CH, Carrau RL, Prevedello DM, Gardner PA, Kassam AB: Defining the nasopalatine line: The limit for endonasal surgery of the spine. Laryngoscope 119: 239-244, 2009

15. Delgado TE, Garrido E, Harwick RD: Labiomandibular, transoral approach to chordomas in the clivus and upper cervical spine. Neurosurgery 8:675-679, 1981

16. Deopujari CE, Karmarkar VS, Shah NJ: Endoscopic approaches to the craniovertebral junction and odontoid process. World Neurosurg 82 Suppl 6: S49-S53, 2014

17. Duntze J, Eap C, Kleiber JC, Theret E, Dufour H, Fuentes S, Litre CF: Advantages and limitations of endoscopic endonasal odontoidectomy. A series of nine cases. Orthop Traumatol Surg Res 100: 775-778, 2014

18. El-Sayed IH, Wu JC, Ames CP, Balamurali G, Mummaneni PV: Combined transnasal and transoral endoscopic approachesto the craniovertebral junction. J Craniovertebr Junction Spine 1:44-48, 2010

19. Fang $\mathrm{CH}$, Friedman $\mathrm{R}$, Schild SD, Goldstein IM, Baredes S, Liu JK, Eloy JA: Purely endoscopic endonasal surgery of the craniovertebral junction: A systematic review. Int Forum Allergy Rhinol 5: 754-760, 2015

20. Fujii T, Platt A, Zada G: Endoscopic endonasal approaches to the craniovertebral junction: A systematic review of the literature. J Neurol Surg B 76: 480-488, 2015

21. Gempt J, Lehmberg J, Grams AE, Berends L, Meyer B, Stoffel $M$ : Endoscopic transnasal resection of the odontoid: Case series and clinical course. Eur Spine J 20: 661-666, 2011

22. Goldschlager T, Hartl R, Greenfield JP, Anand VK, Schwartz $\mathrm{TH}$ : The endoscopic endonasal approach to the odontoid and its impact on early extubation and feeding. J Neurosurg 122 : 511-518, 2015

23. Hadley MN, Spetzler RF, Sonntag VKH: The transoral approach to the superior cervical spine. A review of 53 cases of extradural cervicomedullary compression. J Neurosurg 71(1):16-23, 1989

24. lacoangeli M, Gladi M, Alvaro L, Di Rienzo A, Specchia N, Scerrati M: Endoscopic endonasal odontoidectomy with anterior $\mathrm{C} 1$ arch preservation in elderly patients affected by rheumatoid arthritis. Spine J 13: 542-548, 2013

25. James D, Crockard HA: Surgical access to the base of skull and upper cervical spine by extended maxillotomy. Neurosurgery 29: 411-441, 1991

26. Kahilogullari G, Meco C, Zaimoglu M, Beton S, Meco BC, Tetik B, Unlu A: Pneumocephalus after endoscopic odontoidectomy in a pediatric patient: The lesson learned. Childs Nerv Syst 31: 1595-1599, 2015

27. Kassam AB, Abla A, Snyderman C, Carrau R, Spiro R: An endoscopic transnasal odontoidectomy to treat cervicomedullary compression with basilar invagination. Neurosurgery 8: 198-204, 2005 
28. Kassam AB, Snyderman C, Gardner P, Carrau R, Spiro R: The expanded endonasal approach: A fully endoscopic transnasal approach and resection of the odontoid process: Technical case report. Neurosurgery 57 Suppl 1: E213, 2005

29. Komotar RJ, Starke RM, Raper DMS, Anand VK, Schwartz $\mathrm{TH}$ : Endonasal endoscopic versus transoral microscopic odontoid resection. Innovative Neurosurg 1: 37-47, 2013

30. Kshettry VR, Thorp BD, Shriver MF, Zanation AM, Woodard TD, Sindwani R, Recinos PF: Endoscopic approaches to the craniovertebral junction. Otolaryngol Clin N Am 49: 213-226, 2016

31. La Corte E, Aldana PR: Endoscopic approach to the upper cervical spine and clivus: An anatomical study of the upper limits of the transoral corridor. Acta Neurochir (Wien) 159: 633-639, 2017

32. Landeirol JA, Boechat S, Christoph DH, Gonçalves MB, Castro I, Lapenta MA, Ribeiro CH: Transoral approach to the craniovertebral junction. Arq Neuropsiquiatr 65:1166-1171, 2007

33. Laufer I, Greenfield JP, Anand VK, Hartl R, Schwartz TH: Endonasal endoscopic resection of the odontoid process in a nonachondroplastic dwarf with juvenile rheumatoid arthritis: Feasibility of the approach and utility of the intraoperative Iso-C three-dimensional navigation. Case report. J Neurosurg Spine 8: 376-380, 2008

34. Liu JK, Couldwell WT, Apfelbaum RI: Transoral approach and extended modifications for lesions of the ventral foramen magnum and craniovertebral junction. Skull Base 18: 151166, 2008

35. Liu JK, Patel J, Goldstein IM, Eloy JA: Endoscopic endonasal transclival transodontoid approach for ventral decompression of the craniovertebral junction: Operative technique and nuances. Neurosurg Focus 38: E17, 2015

36. Lopez AJ, Scheer JK, Leibl KE, Smith ZA, Dlouhy BJ, Dahdaleh NS: Anatomy and biomechanics of the craniovertebral junction. Neurosurg Focus 38: E2, 2015

37. Magrini S, Pasquini E, Mazzatenta D, Mascari C, Galassi E, Frank G: Endoscopic endonasal odontoidectomy in a patient affected by Down syndrome: Technical case report. Neurosurgery 63: E373-E374, 2008

38. Mazzatenta D, Zoli M, Mascari C, Pasquini E, Frank G: Endoscopic endonasal odontoidectomy: Clinical series. Spine 39: 846-853, 2014

39. Menezes AH: Surgical approaches: Postoperative care and complications "transoral-transpalatopharyngeal approach to the craniocervical junction." Childs Nerv Syst 24: 1187-1193, 2008

40. Menezes AH, Van Gilder JC: Transoral-transpharyngeal approach to the anterior craniocervical junction: Ten-year experience with 72 patients. J Neurosurg 69:895-903, 1988

41. Menezes AH, Van Gilder JC, Graf CJ, McDonnell DE: Craniocervical abnormalities: A comprehensive surgical approach. J Neurosurg 53: 444-445, 1980

42. Messina A, Bruno MC, Decq P, Coste A, Cavallo LM, de Divittis E, Cappabianca P, Tschabitscher M: Pure endoscopic endonasal odontoidectomy: Anatomical study. Neurosurg Rev 30:189-194, 2007
43. Nagib MG, Wisiol ES, Simonton SC, Levinson RM: Transoral labiomandibular approach to basiocciput chordomas in childhood. Childs Nerv Syst 6: 126-130, 1990

44. Nayak JV, Gardner PA, Vescan AD, Carrau RL, Kassam AB, Snyderman $\mathrm{CH}$ : Experience with the expanded endonasal approach for resection of the odontoid process in rheumatoid disease. Am J Rhinol 21: 601-606, 2007

45. Patel AJ, Boatey J, Muns J, Bollo RJ, Whitehead WE, Giannoni CM, Jea A: Endoscopic endonasal odontoidectomy in a child with chronic type 3 atlantoaxial rotatory fixation: Case report and literature review. Childs Nerv Syst 28: 1971-1975, 2012

46. Pillai P, Baig MN, Karas CS, Ammirati M: Endoscopic imageguided transoral approach to the craniovertebral junction: An anatomic study comparing surgical exposure and surgical freedom obtained with the endoscope and the operating microscope. Neurosurgery 64 (5 Suppl 2): 437-444, 2009

47. Ponce-Gómez JA, Ortega-Porcayo LA, Soriano-Barón HE, Sotomayor-González A, Arriada-Mendicoa N, Gómez-Amador JL, Palma-Díaz M, Barges-Coll J: Evolution from microscopic transoral to endoscopic endonasal odontoidectomy. Neurosurg Focus 37: E15, 2014

48. Qiuhang Z, Feng K, Bo Y, Hongchuan G, Mingchu L, Ge C, Feng L: Transoral endoscopic odontoidectomy to decompress the cervicomedullary junction. Spine 38: E901-E906, 2013

49. Rawal RB, Shah RN, Zanation AM: Endonasal odontoidectomy for basilar impression and brainstem compression due to radiation fibrosis. Laryngoscope 123: 584-587, 2013

50. Sandor GK, Charles DA, Lawson VG, Tator CH: Trans oral approach to the nasopharynx and clivus using the Le Fort I osteotomy with midpalatal split. Int J Oral Maxillofac Surg 19: 352-355, 1990

51. Sawin PD, Menezes AH: Basilar invagination in osteogenesis imperfecta and related osteochondrodysplasias: Medical and surgical management. J Neurosurg 86: 950-960, 1997

52. Seker A, Inoue K, Osawa S, Akakin A, Kilic T, Rhoton AL $\mathrm{Jr}$ : Comparison of endoscopic transnasal and transoral approaches to the craniovertebral junction. World Neurosurg 74: 583-602, 2010

53. Shidoh S, Toda M, Nakajima H, Tomita T, Ogawa K, Kawase T, Yoshida K: Transoral-transpalatal approach and endoscopic endonasal approach for chordomas of the craniovertebral junction. J Neurol Neurophysiol 4:162, 2013

54. Shriver MF, Kshettry VR, Sindwani R, Woodard T, Benzel EC, Recinos PF: Transoral and transnasal odontoidectomy complications: A systematic review and meta-analysis. Clin Neurol Neurosurg 148: 121-129, 2016

55. Singh H, Grobelny BT, Harrop J, Rosen M, Lober RM, Evans $\mathrm{J}$ : Endonasal access to the upper cervical spine, part one: Radiographic morphometric analysis. J Neurol Surg B Skull Base 74: 176-184, 2013

56. Tanriverdi O, Tugcu B, Gunaldi O, Baydin SS, Demirgil BT, Sam B, Kucukyuruk B, Tanriover N: The selective odontoidectomy: Endoscopic endonasal approach to the craniocervical junction. J Craniofac Surg 25: 1482-1487, 2014

57. Visocchi M: Transnasal and transoral approach to the clivus and the craniovertebral junction. J Neurosurg Sci 2015 (Epub ahead of print) 
58. Visocchi M, lacopino DG, Signorelli F, Olivi A, Maugeri R: Walk the line. The surgical highways to the craniovertebral junction in endoscopic approaches: A historical perspective. World Neurosurg 110: 544-557, 2018

59. Visocchi M, La Rocca G, Della Pepa GM, Stigliano E, Costantini A, Di Nardo F, Maira G: Anterior video-assisted approach to the craniovertebral junction: Transnasal or transoral? A cadaver study. Acta Neurochir (Wien) 156: 285-292, 2014

60. Wu JC, Huang WC, Cheng H, Liang ML, Ho CY, Wong $\Pi$, Shih $\mathrm{YH}$, Yen YS: Endoscopic transnasal transclival odontoidectomy: A new approach to decompression: Technical case report. Neurosurgery 63 Suppl 1: ONSE92ONSE94, 2008

61. Yen YS, Chang PY, Huang WC, Wu JC, Liang ML, Tu TH, Cheng $\mathrm{H}$ : Endoscopic transnasal odontoidectomy without resection of nasal turbinates: Clinical outcomes of 13 patients. J Neurosurg Spine 21: 929-937, 2014
62. Youssef AS, Sloan AE: Extended transoral approaches: Surgical technique and analysis.Neurosurgery 66 Suppl 3: 126-134, 2010

63. Yu Y, Hu F, Zhang X, Ge J, Sun C: Endoscopic transnasal odontoidectomy combined with posterior reduction to treat basilar invagination: Technical note. J Neurosurg Spine 19: 637-643, 2013

64. Zenga F, Marengo N, Pacca P, Pecorari G, Ducati A: C1 anterior arch preservation in transnasal odontoidectomy using three-dimensional endoscope: A case report. Surg Neurol Int 6: 192, 2015

65. Zoli M, Mazzatenta D, Valluzzi A, Mascari C, Pasquini E, Frank G: Endoscopic endonasal odontoidectomy. Neurosurg Clin N Am 26:427-436, 2015 